\title{
County Land Resources Management Information System Based on ComGIS
}

\author{
Hai-feng Li \\ Institute of Engineering Surveying. \\ Sichuan College of Architectural Technology \\ Deyang, PR.China \\ Li_hf.student@sina.com
}

\begin{abstract}
Land resources is an important non-renewable resource, using land resources treasuring and rational is the basic policy of our country, so monitoring the land resources utilization real-time, dynamic and managing them effective are the important routines for the land management departments. With the deep of land resources management, relying on the manual operation solely and drawing management model can not meet the needs of modernization. Therefore, the author proposes to use GIS technology to manage land resources effectively. This paper discusses the method of establishing land resources management information system, such as under the $\mathrm{C} / \mathrm{S}$ mode, taking MapInfo and MapX component as the developing platform, Visual Basic6.0 as the developing language, the author also designs the system functions and database in detail, so as to achieve the integrated management of graphics and files about land resources.
\end{abstract}

Keywords-land resources management; ComGIS; MapX; system design

\section{INTRODUCTION}

With the rapid development of China's economic and the deep research of land resources management and reclamation, the land management departments' business has been expanding. Thus, relying on manual operation and drawing management mode solely can not meet the needs of modernization, and then the computer management mode emerges. Land resources management at county as the most basic and forward part of the country's land management system, and how to play its role fully is very important for the policies implementation of land resource management comprehensive. Some ones think that the land resources management agencies are the cornerstone for the country's land resources management, they play a fundamental role in the management of land resources. The level of its efficiency is related to the personal interests directly, and also related to the implement and carrying out of the land resources management laws, regulations and policies. Therefore, it is necessary to take full advantage of modern information technology for management to improve their work efficiency. Geographic information system as an advanced tool has been successfully applied to many area, therefore, establishment land resources management information system based on GIS technology to manage the massive geographic data will greatly improve the work efficiency of the relevant departments.

\section{CHOOSING THE DEVELOPING PLATFORM AND TOOLS}

The appropriate platform must be selected first in GIS application, integrating the features of MapInfo software and users' needs, MapInfo Professional 6.0 and MapX component are chosen as the platform for this system, and Visual Basic6.0 is the developing tool, the component technology is used to GIS in secondary developing of the land information system has become mature [1-3]. Although the land information system has the difference in functions and developing methods because of the different application purpose, from meeting maintenance and management the data of land used to land development evaluation and management for decision analysis, the ideas of system's designing and developing are similar, when the ComGIS is applied.

Component GIS is the GIS collection of object classes which has a standard communication interface and allows cross-language application. Among the components GIS or the components GIS and other components can achieve the intercommunication through the standard communication interface, such intercommunication can even be achieved across the computer. The emergence of ComGIS provides a new developing tool for a new generation of GIS applications. Compared with the centralized GIS, ComGIS has many advantages such as seamless system integration with high efficiency, low cost, compact and flexible, stability and strong transplantation.

\section{THE GOALS OF SYSTEM DESIGN}

The aim of establishing the land resources management information system is to manage the vast amounts and long state land used data efficiently, and to realize the scientific management of land resources, so scientific, informative and intuitive data are provided timely, that will provide a scientific basis for land used planning, farmland protection, decision-making, the dynamic equilibrium of cultivated land summation can be achieved, at last the regional sustainable development is also achieved. Land resources management information system is the space-based information system, which takes the geographic information system technology as the core and uses visualization technology, it also combines with the land management business processes closely and achieves the windows work and automated management, it can provide a good decision support tools for users. 
Designing the county land resources management information system should follow some principles such as the people-oriented, standardization, compatibility, scalability and so on. It should achieve the following three specific aims. First, information searching: that mainly achieves the land resources management data query of the county, countryside and village, it must have the function of query attribute data, and also have the two-way query of graphic and attribute information. Second, statistical analysis and generating reports automatically: it must have the functions of the statistical analysis and also generating reports in county, countryside and village three levels land survey data. Third, generation the thematic maps of land resources management: according to the management needs, system can generate the different levels of land used maps based on administrative units and other thematic maps.

\section{SYSTEM AND DATABASE DESIGN}

\section{A. System design [4,5]}

According to the application range of this system, the C/S model is selected, figure 1 is the structure of three-level framework system based on C/S model, which contains express layer, service layer and data layer. The express layer includes the client applications procedure; service layer includes the application server and background components server, the background components contain MapX and database application components, application servers includes the database management system of Microsoft Access 2000; spatial data layer includes the database engine and database of Microsoft Access 2000. According to the analysis of users' needs, this system contains cadastral management subsystem, land used subsystem, land for construction subsystem and comprehensive maintenance subsystem, figure 2 is the function structure of system.

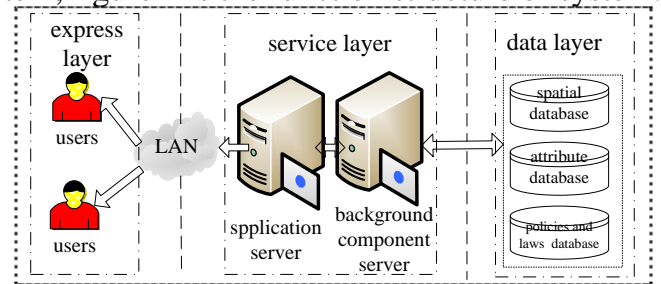

Figure 1. The structure of three-level framework system based on C/S model

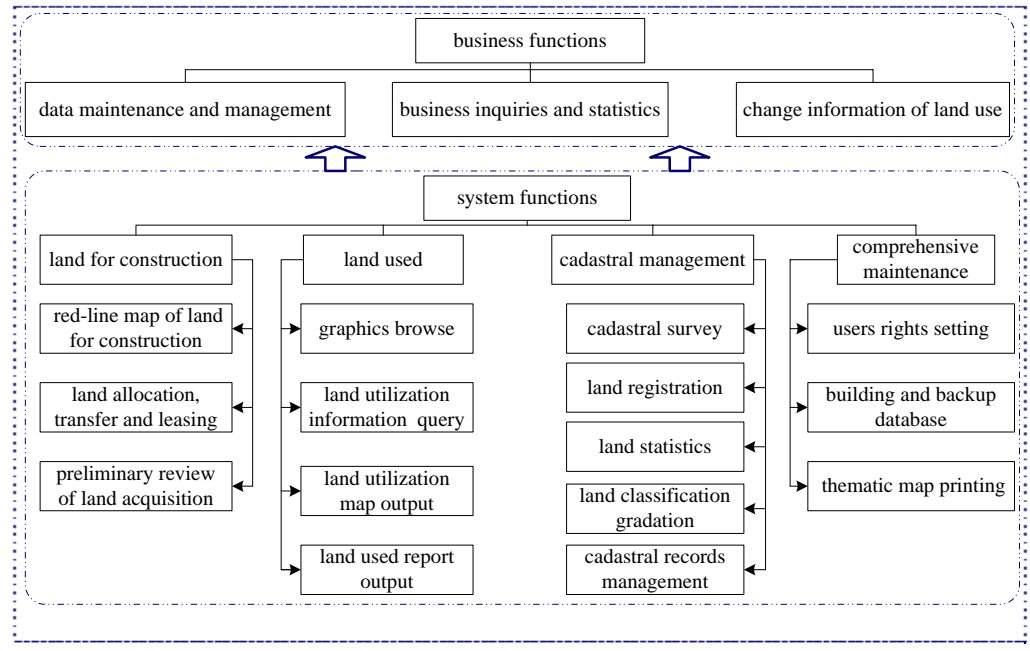

Figure 2. Function structure of system

\section{1) Cadastral management subsystem}

Cadastral management is a series job that country studies the land ownership, natural and economic conditions comprehensively and establishes cadastral atlas to survey cadastral and register land in order to get cadastral information. Land ownership is the core issue. It contains cadastral survey, land registration, land statistics, land classification gradation and cadastral records management. It is the basis of the land management resources system, this subsystem has five functions:

- Initial land registration. Initial land registration is the general registration for all the land within administrative area in a certain period.

- Changing the land registration. Changing land registration is correction the registration after the initial land registration, it is mainly for the land ownership and land use, the purpose is maintaining the current situation of cadastral management information.

- $\quad$ Query and statistics land parcel. Query by attribute: land parcel selected by the land parcel number, the land certificate number, approval form number, registration card number and other sole property information will be displayed flickeringly, while the land parcel information sheet or map will appear; clicking on the cadastral map, land parcel information will be shown on the screen; changing history query: this contains three query methods: the number of land parcel, the changing date and the changing way; land parcel information statistics and query: selecting the search range in the cadastral map and statistical information of the land parcel within the scope will be found out and thematic 
maps of statistical information can be displayed and output.

- Daily routine registering. It mainly solves the problem of land management departments' a variety of forms and card printing automatically to achieve the "paperless office" management.

- Land classification and evaluation. This module can get the grading and evaluating for the results, it is mainly through human-computer interaction, algorithm model, expert scoring and the users input parameters.

\section{2) Land used subsystem}

This subsystem is the management module of the land management department about the land used. it provides the general browsing, graphics browsing, land utilization information query of the administrative units, information searching, statistics and summary the land area, output a variety reports and land used maps with many scales.

\section{3) Land for construction subsystem}

This subsystem has the following functions: It could investigate the location, area, prophase conditions of the acquisition land and create red-line map of land for construction, it also can complete the daily approval job such as land allocation, transfer and leasing, achieving the automation of approval and certification, integrated information query for construction land, the data on the various periods and types for construction comprehensive are counted and analyzed that provides the basis for the leaders' scientific decision-making.

4) Comprehensive maintenance subsystem

Daily data maintenance includes construction the database; back up, download and upload data; output the graphics and attributes of all the subsystems; printing the land parcel map and land certificate.

\section{B. Database design}

GIS data model includes the following categories:

- Raster data model. This model divide ground into uniform grid, each grid has a pixel, codes contained in pixels represent the different geographical features, such as satellite and aerial photography pictures.

- Vector data model. Vector model uses the points, lines and areas to represent the various geographical entities and the relationship between geographic features by recording the coordinates, such as connectivity, proximity and so on.

- The integration of raster and vector data model. Because the grid structure has low accuracy and difficult to establish the network topology, these defects can just be overcome by the vector data structure. Therefore, the system uses the integration of raster and vector data model to form a composite data structure. Land resources management database mainly contains land planning, land used, cadastral management, land valuation, real estate management and other data. All these data have the spatial database and attribute database. spatial data may include cadastral maps, land parcel map, current land used map, general planning map and a variety of different requirements thematic maps, they describe the location of graphic targets and neighborhood such as a large number of boundary points, boundary lines, land parcel, houses. Attribute data is the description information for graphic data.

1) Spatial database design

Supported by the MapInfo platform, spatial database is established, which uses the concept of layers to organize and manage data. According to the different map elements, it can be divided into different layers, they are shown on the same interface and given the feeling of a map. One layer is a data chart containing the graphic object. All elements on the map are divided into layers by the point, line, area, according to the classification and code system, each layer is encoded and classified strictly, in designing and establishing the spatial database, the data type is taken as a basic storage unit, the classification and coding are used to achieve the effective data organization and storage.

2) Attribute database design

The attribute information of land resources management information system is complex, it includes attribute data of each entity and socio-economic statistical data. This system uses the relational database Microsoft Access 2000 to manage the attribute data, it uses the table method for data organization, data tables are in a database for management files. According to the features of the land resources management business, attribute information are stored by the layers standard, that is attribute information of polygons corresponding to the polygons layer, relationship between the graphic information and attribute information is established through a specified keyword.

\section{CONCLUSION}

Using the GIS technology to manage the land resources can achieve the integration of graphics and files, which has the functions of data editing, query, statistical analysis, generation reports and thematic map automatic, it can solve the current inefficient work and the issues in land management to meet the needs of land management business, it also can provide the basis of information support and decision-making in the development and utilization evaluation and planning of land resources, if the county departments wildly use the geographic information system, the standardization of land resources data will be greatly accelerated. In addition, with the social share requirements of land resources growing, WebGIS based on internet provides an effective approach for users and the GIS information provider, which offers opportunity for traditional geographical information system development[6]. It changed the processes and methods of GIS data in acquisition, transmission, publishing, sharing, application and visualization, so that the internet users can receive the geographical information they need anywhere and make the geographic information share for the entire community really. 


\section{REFERENCES}

[1] XU Aiping,XU Wuping. THE COMPONENT TECHNIQUE AND COMGIS[J].JOURNAL OF GEOMATICS,2001,2:32-36.

[2] LIU Dan,DENG Kun, PENG Lihui. Research and Application of Components Technology in Geographic Information System[J]. EARTH SCIENCE-JOURNAL OF CHINA UNIVERSITY OF GEOSCIENCES,2002,27(3):263-266.

[3] ZENG Hang,LI Jianwei,SONG Yang,etc. Application of COM Technology in Geographic Information System[J]. JOURNAL OF CHONGQING NORMAL UNIVERSITY (NATURAL SCIENCE EDITION) ,2001,18(4):51-56.
[4] CHEN Can PAN Jianjun SHAO Jinda. Design and Application of Land Management Information System in Wenzhou City Based on MapX[J]. CHINESE AGRICULTURAL SCIENCE BULLETIN,2009,25(10):268-272.

[5] LI Wenshi. Design of the Land Management Information System of Township Based on ComGIS[J]. JOURNAL OF QUANZHOU NORMAL UNIVERSITY ,2009,27(6):80-84.

[6] WEI Haiyan KANG Jian REN Zhiyuan.Design and Exploitation of Land Management Information System of Xi'an Based on WebGIS[J]. JOURNAL OF ARID LAND RESOURCES AND ENVIRONMENT,2005,19(5):20-24. 